\title{
Career Counselling: The Usefulness of the Career Interest Profile (CIP)
}

\author{
Annamaria Di Fabio \\ University of Florence \\ Jacobus Gideon Maree \\ University of Pretoria
}

Address correspondence to Professor Annamaria Di Fabio, Dipartimento di Psicologia, Università di Firenze, via di San Salvi, 12, Complesso di San Salvi, Padiglione 26, 50135 Firenze, Italy. E-mail: adifabio@psico.unifi.it

This study reports the findings from exploratory career counselling with Italian undergraduate university students using the Career Interest Profile (CIP). The participants $(n=178$, females $=51.69 \%$; mean age 22.28, SD $=1.59$ years) received elective career counselling on campus. The students completed the CIP and the Self-Directed Search (SDS). Data were analyzed using both qualitative and quantitative approaches. The CIP yielded satisfactory results with regard to trustworthiness and intercorrelations with the SDS and provides career counsellors with a useful instrument for the identification of interest profiles of Italian undergraduate university students. Participants reported being enabled to explore prospective career interest areas using career-story narratives for constructing life trajectories and enhanced development of their career stories.

Keywords: career counselling, Career Interest Profile, career story, combined quantitative-qualitative assessment, life design, psychometric properties, university students, validity

The theory and practice of career counselling is clearly in need of a shift in paradigm in the 21 st century. The loss of stable structures and predictable trajectories calls for a science of intervention that deals with self-construction and career designing (Savickas, 2011). The life design paradigm was developed by Savickas et al. (2009) for this very reason. Career counselling interventions in the postmodern era require a narrative or life story (storied) approach to counselling (Maree, 2007; Savickas, 2005, 2009, 2010), and elicitation and utilisation of life stories play a key role in life design counselling (Savickas et al., 2009).

Contemporary theories on and goals in career counselling, including the historical and philosophical underpinnings of qualitative as well as quantitative approaches, can be merged to provide a viable framework for the interpretation and explanation of career-related behaviour and thus promote meta-(self-)reflection for life design and living a successful life (Duarte, 2010 Maree, 2010b; Savickas et al., 2009). This approach offers a useful strategy to help clients face repeated transitions as and when they occur. Counsellors should endeavour to be useful to clients by creating spaces where clients can discover their personal characteristics and share those (past and present) micro-career stories that they are ready to share. The aim is to enable clients to combine these micro-narratives into a macro-narrative (Savickas, 2011). This should enable them to deal with transitions and rise above the past and present challenges and perceived weaknesses that jeopardise their chances to design successful lives, enter the world of work and make social contributions.

\section{Using a Combined Quantitative-Qualitative Approach}

Different types of interest-related assessment instruments (quantitative and qualitative) are at counsellors' disposal. However, very few instruments combine aspects of both modes of inquiry in a manner that, firstly, overlaps both modes of assessment and, secondly, enables counsellors to help clients identify and understand their life themes better. The procedure described in the next section provides counsellors with a viable strategy to achieve this aim.

The authors of this article believe that the value of a combined quantitative-qualitative approach in promoting a deeper understanding of the notion of career as story cannot be emphasised strongly enough. The postmodern narrative approach, in conjunction with a consideration of the results obtained by often out-of-date quantitative instruments and positivist career orientations, may well help professionals resolve the typical problems encountered in present-day practice (Porfeli, 2003).

Not a question of one approach versus another. Qualitative techniques are used to augment quantitative techniques during career counselling and vice versa (Maree, 2012). It is not a question of one approach versus another or one approach being 'better' or worse than another. Rather, the aim of the approach advocated here is to use the best of both techniques (combining and drawing on the results of quantitative and qualitative assessment) in career counselling. Such orientation is consistent with the life design theoretical framework (Savickas et al., 2009) and is being increasingly advocated globally by leading researchers (McMahon \& Patton, 2002). This style of career counselling promotes intention and action through story-telling (Savickas, 2011). Moreover, by following a combined approach that has transactionist, interactionist and discursive elements, clients are enabled to reflect on their own reflections under the attentive and caring eye of a counsellor. Guided meta-reflection thus takes place. Clients tell their stories, discover who they are and not only choose careers but, more importantly, discover their major life themes. They are encouraged to find meaning in their own responses to ca- 
reer-counselling questions and to advise themselves through guided meta-reflection (see below: they are guided to identify their main life themes first and then decide on a job or a career) (Maree, 2012). Clients can, of course, also re-author (aspects of) their stories, if necessary.

\section{Meta-Reflection}

Whereas the role of counsellors as co-constructors of meaning in the stories and lives of their clients is generally acknowledged and accepted, the authors of this article maintain that clients' own voice is the one voice that will remain contemporary, valid, reliable and enduring in their lives. Clients can draw on this well of knowledge and expert opinion (their own voice) whenever they encounter a new crossroads in their lives. It is the task of counsellors to help their clients meta-reflect on their life stories in such a way that they can listen to the voice within and advise themselves on how to construct, design and actually live successful lives because because people are capable of making the 'best' career-related choices at any specific moment (Lankton \& Lankton, 2011). The significance clients attach to their reflections and meta-reflections is central to their life designing of which career-related choices are only one (albeit important) facet.

\section{Goal of the Study}

The core theme of the study was the usefulness and value of the Career Interest Profile (CIP) (Maree, 2006, 2007, 2009, $2010 \mathrm{a}, 2010 \mathrm{~b}$ ) to explore career narratives with student participants. The evidence would address the perceived usefulness of the $C I P$ with Italian student counselees. It would also contribute to the evidence on the trustworthiness and construct validity of the CIP when administered to university students. An ancillary goal was to determine the quality of the students' experiences with the CIP, which would be important for its use with similar student populations.

\section{Method}

\section{Participants}

The participants in the study were 178 students at the University of Florence in Italy. Convenience, availability sampling was used to select the participants who had to be students who had sought career counselling. The participants were between 21 and 27 years of age $(M=22.28, S D=1.59)$. Eighty-six men $(48.31 \%)$ and 92 women $(51.69 \%)$ constituted the sample (men: $\mathrm{M}=21.81, \mathrm{SD}=1.27$; women: $\mathrm{M}=22.72$; $\mathrm{SD}=1.74$ ).

\section{Measures}

Although the primary measure of study was the CIP, students also took the $S D S$ to determine if correlations between the CIP and Self-Directed Search Questionnaire (SDS) (Polácek, 2003) categories were satisfactory. The instruments are described next.

The Career Interest Profile (CIP). The CIP is divided into four parts: biographical details, family influences, working information (Part 1); career category preferences/dislikes (Part 2; see Table 1); career choice related questions (Part 3); and career-story narratives (Part 4). Participants are requested to complete Part 1 followed by Part 2 and Part 3 and, eventually, Part 4. Part 2, which deals with "career category preferences/dislikes", requires participants to choose and rank their five preferred career categories from a total of 19 broad, encompassing career categories in order of preference and then rank their five least-liked career categories in order of dislike. Participants are asked to underline the specific occupations in which they are more interested than others in green and specific occupations in which they are less interested than others in red. The 19 categories are listed and briefly defined in Table 1.

Determining a person's interests (a facet of his or her personality configuration) remains a key aspect of career counselling. Awareness of one's interests contributes meaningfully to choice-making and career development (Savickas \& Spokane, 1999). As stated by Maree (2010a, 2010b), the 19 career categories presented in the CIP provide counsellors with a starting point for elucidating and discussing relevant career profiles in greater depth.

The CIP focuses on and merges several methods of assessing clients' career interest profiles, namely testing clients (using formal questionnaires), the interview method (asking clients about their interest category patterns), the observation method (observing how clients respond both verbally and non-verbally to questions) and administering informal questionnaires (the last three methods are rooted in narrative theory). The CIP was designed to help clients narrate their career stories, thus enabling them to listen to, authorise and fine-tune these stories, and, ultimately, become actively involved in the process of self- and career construction. Using the instrument, clients are gently guided to reflect and meta-reflect on their own career-related responses. The strategy incorporated in the CIP provides career counsellors with a strategy to help clients not only choose 'appropriate' careers but, more importantly, advance their unfinished stories, construct life trajectories, construct themselves and use their careers to design and live successful lives. The CIP shows adequate psychometric properties (Maree, 2006) in terms of test-retest reliability, content and criterion-related validity in comparison with the SDS.

The CIP (including its narrative, life-style, life-story supplement) was developed in response to the need for multiple approaches to the collection of data as a preliminary step in assisting clients to make appropriate career choices and design successful lives. The CIP can be administered to clients, either individually or in groups, at the beginning of a given year and again at the end of the year if necessary.

The Self-Directed Search Questionnaire (SDS) (Holland, Powell, \& Fritzsche, 1994). The Italian version of the SDS by Polácek (2003) is based on the theory of personality types developed by Holland (1959) and is divided into five sections: Activities, Competencies, Occupations, Self-evaluation I, and Self-evaluation II. Items are grouped according to the six Holland interest fields (Realistic, Investigative, Artistic, Social, Enterprising and Conventional) within each section. The items of the first three sections (Activities, Competencies, and Occupations) have dichotomous response categories, namely Yes $=1$, $\mathrm{No}=0$. The number of items in each of the first three sections is as follows: 66 items (11 for each Holland interest field) for the Activities section; 66 items ( 11 for each Holland interest field) for the Competencies section; and 84 items (14 for each Holland interest field) for the Occupations section. In the two sections dealing with Self-evaluation, participants are asked to rate themselves in relation to a set of skills on a Likert scale from $1=$ low to $7=$ high. The first section includes mechanical skills $(R)$, scientific skills (I), artistic skills (A), teaching skills (S), selling skills $(E)$ and administrative skills $(C)$; the second section includes manual skills $(R)$, mathematics skills (I), musical skills $(A)$, understanding others skills (S), management skills (E) and skills in relation to office work (C). 
Table 1

Interest Category

1. Practical-technical (PT)

2. Practical-creative and consumer science (PCCS)

3. Musical (MU)

4. Arts (painting, sculpture and decoration) and culture (APSDC)

5. Word artistry (WA)

6. Office-based (administrative, clerical and organisational) activities (OACOA)

7. Marketing (MA)

8. Computer industry and technology (CIT)

9. Mathematics and accounting industry (MAI)

10. Social, care-giving, and community services and teaching (SCCST)

11. Entrepreneurship: running and maintaining a personal business (ERMPB)

12. Adventure, plants, animals and the environment (APAE)

13. Sport (S)

14. Research (R)

15. Medical and paramedical services (MPS)

16. Tourism, hospitality and the tourist transport industry (THTTI)

17. Legal practice and security services (LPSS)

18. Executive and management practice (EMP)

19. Engineering and the built environment (EBE)
Interest area description

machinery (heavy or light)

creative work

performing, teaching and producing, as well as in music-related products.

producing or manufacturing artistic products and/or buying/selling artistic or decorative products.

verbal activities such as reading, talking and acting.

the security and predictability of an office-based environment.

marketing as a high-level discipline.

gaining computer skills and knowledge and working with computers.

ordering ideas numerically.

helping other people.

making a success of a personally owned business.

some aspect of the natural world.

participating in one or several sports and deriving pleasure from a favourite sport.

research procedures and methods.

looking after and treating sick and injured people, animals or birds.

providing competitive services in diverse occupations such as running a bed and breakfast establishment.

the law as a mechanism for regulating human behaviour.

leadership and ordering ideas interactionally.

design, construction, engineering and related activities.
For each interest field (R, I, A, S, E, C), a total value is obtained by adding the raw scores for the activities, skills, professions and self-evaluation sections. Regarding the reliability of the six areas of the SDS, the coefficients of the sections that make up each area were satisfactory in the Polácek (2003) study. The overall internal consistency of the six areas, too, was good with alpha coefficients greater than .80: Realistic $(\alpha=.86)$; Investigative ( $\alpha=.84)$; Artistic $(\alpha=.81)$; Social $(\alpha=.82)$; Enterprising $(\alpha=.85)$; and Conventional $(\alpha=.83)$. The Holland hexagon model fitted the Italian context well (Polácek, 2003).

Qualitative techniques. Qualitative data were collected during in-depth (one-on-one, as well as group and focus group, semi-structured) interviews and oral discussions with the participants and by observing them. (For the interview schedule, see the narrative sections of the CIP.) The CIP and its narrative supplement were employed to facilitate data collection from the narrative paradigm.

\section{Procedure}

The Italian translation of the CIP (Maree, 2010a, 2010b) by Maree and Di Fabio, its narrative supplement and the SDS in November 2011 were administered at the University of Florence in November 2011 over a period of one week. The process described earlier (see: Measures) was strictly adhered to. A focus group interview was held before and after the assessment with a randomly selected group of eight participants to establish how they experienced the sessions.

\section{Data Analysis}

Quantitative data analysis: Criterion-related validity. Spearman correlations between CIP and SDS ranks were calculated (based on all 19 career categories in the case of the CIP and on all six categories in the case of the SDS). In this study, high and moderate effect sizes were considered practically significant.

Kolmogorov-Smirnov and Shapiro-Wilks tests were calculated to see if the rankings for the $19 \mathrm{CIP}$ careers and for the six $S D S$ categories were normally distributed.

Qualitative data. The first, third and fourth parts of the CIP constitute the narrative part of the questionnaire. The following (inductive) approach, which is central to the CIP-style of qualitative data analysis, was adopted in order to analyse the CIP data obtained from the participants' responses to the three sets of questions contained in Part 1, 3 and 4 . The counsellor reads the client's responses back to him or her, asks for clarification and 
unobtrusively facilitates inductive data analysis. The client's responses are studied carefully to explore patterns, themes and subthemes. When the similarity between the responses to questions in the CIP is unobtrusively pointed out, inherent themes and subthemes can emerge from the qualitative data. Once the point of data saturation has been reached and themes and subthemes have emerged (e.g., a deep desire to look after others and make a difference in the lives of others), Part 2 of the CIP is revisited, and the data are triangulated; in other words, counsellor and client jointly try to create a combined set of themes and subthemes. (Ideally, other interest inventories should be administered as well to triangulate the findings even further.)

Interest Exploration. The entire process of career counselling centres on the guiding principle of allowing clients to listen to and advise themselves on interest-related themes and subthemes but also on their ultimate 'destiny' - for example, to defend the voiceless or to become very wealthy. Counsellors provide a willing and empathetic audience and, in the process, act as editors of clients' life stories. The process is concluded when counsellors prompt clients to take action by, for example, actively doing job analysis in various forms, including surfing the internet, and reporting back to them once they (the clients) have taken sufficient action and acquired a keen sense of what their destiny is and what steps can be taken (jobs chosen and executed) to reach that destiny (realise their main life themes). In the present study, the participants' responses were read back to them verbatim, and they were told about the importance of identifying their major life themes first and only then deciding on a career as a vehicle to realise these themes and make social contributions. They were then asked to 'reflect upon [their] reflections' and to tell the counsellors which themes they could identify from their responses. Minimal interpretation was done by the counsellors.

Experiential value. A deductive approach was followed in the analysis of the focus group participants' responses to how they experienced the CIP process of counselling. The data were evaluated and categorised according to predetermined themes found in the literature (Creswell, 2007). In the data analysis, the documented data were organised and themes, subthemes and categories identified. Predetermined themes were also identified from the literature (Maree \& Sommerville, 2008). The four dimensions listed by Maree and Sommerville (2008), namely Creativity and enjoyment, Accent on feelings and life story, (Initial) Ambiguity regarding the purpose of the narrative questionnaire, and Time spent with participants were used as the predetermined themes. These themes relate to the central thesis of the study (narratability) and were used to elaborate on the central thesis. In order to realise the full potential of the co-constructive nature of interpretivist research, our intention was not to provide interpretations but to present a nuanced understanding of the participants' self-construction process as it emerged during the study. Verbatim responses from the participants were provided to illustrate the emergence of significant themes.

Ethical issues. Written permission to conduct the study was obtained from the relevant authorities as well as from the participants. The assurance was given that no individual would be identified. All information that could identify an individual was disguised or omitted. Ethical measures to ensure the research participants' well-being were implemented throughout the study. The questionnaires were administered by a professional psychologist. The researchers gave feedback to the partici- pants during all the phases of the study. The research findings were released in a responsible manner (Whitley, 2002).

\section{Results}

\section{Experiential or Process Evidence}

The in-depth interviews revealed that the activities and careers that constitute the CIP career categories were familiar to the participants and afforded them an opportunity to express their interests without the restrictions that characterise the SDS, for instance (such as the strictly structured approach that leaves little room for creativity and self-construction). Some of their responses 1, which substantiate the aforementioned claim, were:

"it was interesting and important to peruse all 19 CIP categories. Doing so introduced me to many different areas of interests not referred to in the SDS" (Participant 9, male).

"This exercise was very useful. I enjoyed the opportunity to consider those professional categories that I dislike and to rank them. Other questionnaires do not allow this" (Participant 23, female).

"I enjoyed this exercise because I was given the opportunity to reflect on a broader array of categories. This stimulated my thinking. The SDS only allows yes or no answers, which I find limiting and narrow" (Participant 42, female).

"The exercise allowed me to reflect on my interests without any restrictions. I found it very useful to reflect on categories and careers that I like and dislike. In addition, I enjoyed the opportunity to express myself more satisfactorily instead of merely answering yes or no" (Participant 53, male).

The analyses of the participants' responses confirmed the usefulness of the CIP to career counsellors in that it allows clients to listen to and advise themselves not only on their main and sub-career interest-related themes but also on their ultimate 'destiny'.

Some of their responses ${ }^{1}$, which substantiate the aforementioned claim, are listed below.

"My primary interests in the social area and in helping others were confirmed. However, I now understand that I should also consider my interest in research. I believe my plan to enroll in a PhD programme is consistent with my interest profile and envisaged career path" (Participant 65, female).

"Reflecting on areas that interest me as well as on those in which I am not interested enabled me to see that my ideal to become a physician is appropriate. It reflects all five of my main interest areas" (Participant 87, male).

"The questionnaire enabled me to become more aware of my interests, which are consistent with my dream to become an engineer" (Participant 27, male).

"Completing the questionnaire, which confirmed my strong interest in the built environment, art and entrepreneurship, made me progressively more aware that my choice of architecture as a field of study is in line with my interest areas" (Participant 58, female).

Nonetheless, uncertainty regarding the purpose of the narrative parts of the questionnaire (the CIP) was expressed by some participants as follows:

"It took me a while but I managed to dispel the few hesitations I had at the beginning" (Participant 30, male.)

"I'm quite satisfied. I do wish that we could have follow-up sessions to discuss the practical aspects that were suggested to us, though" (Participant 48, female). 
"Initially, the purpose of the questionnaire was not clear to me because I am not used to being asked to respond to these kinds of questions." (Participant 98, male).

"This is unlike anything I have done before. It felt strange in the beginning" (Participant 12, male).

The semi-structured, individual, in-depth interviews with the participants on the usefulness of the process yielded interesting data. The findings indicated that the participants were positive about the assessment along the following three themes: 1) creativity and enjoyment; 2) accent on feelings and lifestyle; and 3) time spent with participants.

The first category (creativity and enjoyment) refers to the creative processes involved in the acquisition of enhanced self-awareness and the construction of a new chapter in a person's career and life story. The CIP facilitates realization of creativity and enjoyment by facilitating in-depth self-reflection by participants on themselves in an uncomplicated manner. Some responses, which substantiate the aforementioned claim, are listed below.

"The experience made me realize and appreciate things I had never considered before and proved very useful" (Participant 39, male).

The exercise confirmed many of my interests. The deep sense of understanding myself that I acquired improved my self-confidence!" (Participant 18, female).

"I enjoyed working in an unstructured manner; being able to express myself freely without being restricted by yes or no answers (Participant 24, female).

"It was pleasant to be allowed to express myself openly in writing; the questions made me think deeply about myself' (Participant 101, male).

The second category (accent on feelings and lifestyle) refers to participants' feelings and emotions and/or to perceived changes in their modes of thinking or acting which add meaning to their career and personal life. Example statements were:

"I am touched. If the ultimate goal was to reveal my weaknesses and uncertainties, the intervention was great. I felt so enthused; almost as if I could handle the instability of my reality" (Participant 3, female).

"As you could see, I cried when I answered certain questions. I am okay now; it's just that I haven't talked about these emotions in a long while" (Participant 17, female).

"The questions helped me see once more who I really am and what I really want to be. I must be free ... I feel vindicated. I cannot allow others to decide on my behalf" (Participant 23, male).

"I'm satisfied because it now seems as if my interests offer me a solution to my feelings of frustration. It affords me the possibility to do something that has meaning instead of just existing from day by day, delaying asking myself critical questions" (Participant 11, male).

The third category (time spent with participant) refers to participants' perceptions about the time spent and about the experience of comfort during the session. Example statements were:

"The time just flew by while we answered the questions. It was a captivating and very interesting experience. I enjoyed the session very much even though, at times, it was challenging to provide answers" (Participant 13, male).

"I became more aware of myself in a relatively short space of time. I am glad I spent the time on myself because I now realize I should 'make' and not merely 'suffer' choices" (Participant 107, female).
"I enjoyed the respect shown by not rushing me" (Participant 118, male).

"It was great not to be rushed. Furthermore, I learned so much from listening to others' stories and honesty and pain" (Participant 134, female).

Criterion-related validity. Table 2 shows Spearman correlations between the CIP and the SDS ranks (based on all 19 career categories in the case of the CIP and on all six categories in the case of the SDS). More direct comparisons were not possible because of the absence of a one-to-one correspondence between the 19 CIP career categories and the six SDS categories.

We, as the researchers concerned, were interested in seeing if the correlations between CIP and SDS categories were satisfactory. Table 3 shows the highest (positive) correlations with either a large effect size or a medium effect size.

The Kolmogorov-Smirnov and Shapiro-Wilks tests revealed that the rankings for all of the 19 CIP careers and for all of the six $S D S$ categories were not normally distributed. For this reason, and because the data were ordinal rather than interval-scaled, we used Spearman correlations because (1) Spearman correlations are associated with ranks, (2) the ranks were not normally distributed, and (3) the relationship between the CIP and SDS ranks might not be linear. (In our analysis, the Spearman and Pearson correlation coefficients were similar.) Effect sizes for correlations are generally based on the correlation coefficient itself.

Tables 2 and 3 show that in the vast majority of cases where this was to be expected, practically significant correlations between the CIP and SDS categories occurred. We concluded that the correlations between the CIP and SDS categories were highly satisfactory. Interestingly, the only five practically significant negative correlations were between a) Practical-technical $(C I P)$ and Engineering and the built environment $(C I P)$ on the one hand and Social $(S D S)$ on the other; b) Social services $(C I P)$ and Realistic $(S D S)$; c) Arts (painting, sculpture and decoration) $(C I P)$ and Realistic (SDS); as well as between d) Research $(C I P)$ and Investigative (SDS).

In the case of Part 2 of the $C I P$, the results yielded a number of fields of study; in the case of the qualitative part of the CIP (Parts 1, 3 and 4), the participants' reflections on their own reflections uncovered major life themes (in line with career construction theory) (Hartung, 2011; Savickas, 2005). Examples of statements that pertain to career construction-related life themes were:

a. Role models: "My role model is my dissertation supervisor because she supervises me passionately. She loves her work but also thinks that one's personal life is very important' (participant 22, female).

b. Magazine: "I enjoy reading historical journals. I believe that understanding history is fundamental to understand current reality. I have always loved history. I would love to become a history teacher so I can enjoy teaching important historical concepts to young learners" (participant 54, male). c. Favourite saying: " 'Without music, life would be meaningless.' Music has always been an important part of my life. I can't live without music and it just has to form a significant part of my work life" (participant 76, female).

d. Earliest memories/ biggest problems when I was young: "When I was young my brother broke a vase in the living room. My parents accused me and wanted me to confess to having broken the vase. I experienced a strong sense of being treated in an unfair manner. Perhaps my interest in law 
Table 2

Spearman Correlations Between CIP and SDS Categories

\begin{tabular}{|c|c|c|c|c|c|c|}
\hline & $\mathrm{R}$ & I & $A$ & $S$ & $E$ & C \\
\hline CA1 & $.24^{*}$ & -.15 & .17 & $-.26^{\star *}$ & .06 & -.18 \\
\hline $\mathrm{CA} 2$ & .01 & .08 & -.11 & -.11 & $.22^{*}$ & .14 \\
\hline CA3 & -.03 & .10 & $.21^{*}$ & .05 & .14 & .05 \\
\hline CA4 & $-.29^{*}$ & -.09 & $.27^{\star}$ & .16 & $.23^{*}$ & .04 \\
\hline CA5 & -.23 & .10 & -.17 & .04 & -.12 & .18 \\
\hline CA6 & .02 & .11 & .07 & -.07 & -.10 & $.20^{*}$ \\
\hline CA7 & .01 & .08 & .10 & -.05 & $.36^{* *}$ & -.05 \\
\hline CA8 & $.23^{*}$ & -.08 & .07 & $.24^{\star}$ & $.26^{*}$ & -.13 \\
\hline CA9 & -.04 & $.26^{*}$ & .13 & .19 & .02 & $.32^{\star \star}$ \\
\hline CA10 & $-.40^{\star *}$ & $-.30^{\star \star}$ & .02 & $.48^{\star \star}$ & .09 & -.23 \\
\hline CA11 & .01 & .11 & .06 & .09 & -.11 & $.21^{*}$ \\
\hline CA12 & $.38^{* *}$ & $.27^{\star}$ & .17 & .08 & -.11 & .12 \\
\hline CA13 & .03 & -.20 & .07 & .11 & $.20^{\star}$ & .04 \\
\hline CA14 & $.22^{*}$ & $.51^{\star \star}$ & .02 & -.23 & .01 & $.22^{*}$ \\
\hline CA15 & $.32^{* *}$ & $.38^{\star *}$ & -.03 & .17 & .07 & .06 \\
\hline CA16 & .06 & .04 & -.14 & $.20^{\star}$ & .01 & .13 \\
\hline CA17 & -.06 & .01 & -.24 & -.05 & .06 & .03 \\
\hline CA18 & -.19 & -.05 & -.08 & .19 & $.48^{* *}$ & .01 \\
\hline CA19 & $.41^{* *}$ & .14 & -.03 & $-.40^{\star *}$ & .03 & .19 \\
\hline
\end{tabular}

Note. ${ }^{*}: p \leq 0.05 ;{ }^{* *}: p \leq 0.01$.

emerged from this incident. I do not want anyone else to experience that feeling of disempowerment' (participant 145, male). These themes were exceptionally useful in terms of their potential to enable the participants to explore career-related meanings.

\section{Discussion}

Sufficient evidence was found as regards the trustworthiness and criterion-related validity of the CIP when administered to these counsellees. Moreover, the quality of the students' experiences with the CIP was evidenced abundantly. This potentially bodes well for its use with similar student populations. Participants reported being enabled to explore prospective career-related interest areas using career-story narratives for constructing life trajectories. Consistent with the aims of life designing intervention, participants reported enhanced development of their career and life stories (Di Fabio \& Maree, 2011, in press). The value and importance of a focus on the process of career counselling (Barclay, in press; Barclay \& Wolff, 2011) was accordingly demonstrated. Future research could consider including larger and more diverse groups of participants and administering narrative questionnaires appropriate for assessing stability of the findings, including, for instance, the Future Career Autobiography (Rehfuss, 2009).

The correlational evidence is consistent with that from previous studies (e.g., Di Fabio, 2012; Maree \& Sommerville, 2008). For example, an explanation for the first three negative correlations could be that whereas people who show a high interest in Social services often tend to be verbal and extroverted (mostly dealing with other people) (Holland et al., 1994), people who show an interest in Practical-technical (e.g., electricians) and Engineering and the built environment (e.g., mechanical engineers) often tend to be non-verbal and introverted (often dealing with inanimate in- struments) (Holland et al., 1994). An explanation for the fourth negative correlation (between Arts and Realistic) could be that whereas people who show an interest in Art often prefer jobs in free and unstructured environments and jobs where they can use their creative talents (Gevers, Du Toit, \& Harilall, 1995), people who show an interest in Realistic often tend to prefer orderly and systematic environments where they can work with tools and objects. Similarly, an explanation for the fifth negative correlation could be that whereas people who show an interest in Social services often tend to be extroverted and socially oriented, people who show an interest in Research tend to be more introverted and less socially oriented (Holland et al., 1994). It is recommended that future research should focus on the concurrent validity of the CIP with decision-making variables such as career decision-making difficulties and other emerging constructs linked in the literature with aspects of decision making.

\section{Implications for Career Counselling with University Students}

The CIP can be used by counsellors to assist clients with the following features of questionnaire interpretation: identification of their own career interest profiles, understanding different aspects of their career-related interests and facilitating discussion. Enabling clients to listen to themselves and subsequently move from inaction to action includes making appropriate career choices that can help them construct themselves by realising major life themes and thereby turning their pain into victory, sadness into happiness and deprivation into a social contribution. In other words, whereas describing clients' emotional, social and socio-economic states or conditions can serve a useful purpose in terms of highlighting challenges clients face at a certain point in time, these states or conditions need neither define who clients really are nor who they can become (self-construct). 


\begin{tabular}{|c|c|c|c|}
\hline & CIP & $S D S$ & $p$ \\
\hline 1 & CA14 & I & $.51^{\star \star}$ \\
\hline 2 & CA10 & $S$ & $.48^{\star \star}$ \\
\hline 3 & CA18 & $E$ & $.48^{\star \star}$ \\
\hline 4 & CA19 & $\mathrm{R}$ & $.41^{\star *}$ \\
\hline 5 & CA15 & 1 & $.38^{\star \star}$ \\
\hline 6 & CA12 & $\mathrm{R}$ & $.38^{\star *}$ \\
\hline 7 & CA7 & $E$ & $.36^{\star \star}$ \\
\hline 8 & CA15 & $\mathrm{R}$ & $.32^{\star \star}$ \\
\hline 9 & CA9 & C & $.32^{\star *}$ \\
\hline 10 & CA4 & $A$ & $.27^{\star}$ \\
\hline 11 & CA12 & I & $.27^{*}$ \\
\hline 12 & CA9 & 1 & $.26^{*}$ \\
\hline 13 & CA8 & $E$ & $.26^{*}$ \\
\hline 14 & CA1 & $\mathrm{R}$ & $.24^{*}$ \\
\hline 15 & CA8 & $S$ & $.24^{*}$ \\
\hline 16 & CA8 & $\mathrm{R}$ & $.23^{*}$ \\
\hline 17 & CA4 & $E$ & $.23^{*}$ \\
\hline 18 & CA14 & $\mathrm{R}$ & $.22^{*}$ \\
\hline 19 & $\mathrm{CA} 2$ & $E$ & $.22^{*}$ \\
\hline 20 & CA14 & $\mathrm{C}$ & $.22^{*}$ \\
\hline 21 & CA3 & $A$ & $.21^{*}$ \\
\hline 22 & CA11 & C & $.21^{*}$ \\
\hline 23 & CA16 & $S$ & $.20^{*}$ \\
\hline 24 & CA6 & $\mathrm{C}$ & $.20^{*}$ \\
\hline 25 & CA13 & $E$ & $.20^{\star}$ \\
\hline
\end{tabular}

Note. All correlations in Table 3 are statistically $\left({ }^{*}: p \leq 0.05\right.$; $\left.^{* *}: p \leq 0.01\right)$ and practically significant. For the purposes of this article, $p \geq 0.25$ indicates medium effect size and $p \geq 0.45$ large effect size (Ellis, 2005) (i.e., only those $p$ 's that are statistically and practically significant are highlighted) (Ellis, 2007, personal communication); $\mathrm{N}=178$.

In the words of the song: "One is only poor if they choose to be" (Parton, 1994, p. 19).

Counselling styles interact with people's career choices and actions in a way that often either encourages or discourages them to take personal responsibility for these choices and to engage actively in career-related activities that may help them make informed career-related decisions. Career counsellors should be flexible and open-minded in their approach to data collection. Since objective as well as subjective data are needed to make well-informed and appropriate career decisions, the greater the number of useful methods, both objective and subjective, for obtaining preliminary data, the better. The CIP (with its narrative supplement) appears to be an instrument that can be used to achieve this aim. Based on the premise that career counselling should in the final instance depend on an analysis of autobiographies and carefully assembled and coherent meanings rather than on counselling techniques or on questionnaires that test aptitudes and personality, the CIP offers career counsellors the opportunity to assist clients to interpret their interests, potential and career values and so design a career plan to help them realise their life themes.

A brief caveat is appropriate here. A list of CIP career categories that are linked with possible careers (based on empirical work) is available. However, this list should be used only as a broad guideline to facilitate discussions on possible fields of study or careers. The list should never be used as a substitute for meticulous post-assessment activity, which includes various facets of job analysis. Using the list as an uncomplicated way of 'matching' personal career interests and possible careers would make a mockery of the whole CIP intervention. A basic assumption is that the CIP will be used for scholars and students, but our hope is that the CIP will eventually be used for people of all ages.

\section{Limitations of the Study}

This was a limited study and should be regarded as 'work-in-progress'. We are currently analysing our second stream of data. The results presented here need to be verified in future research on groups of participants more widely representative of Italian students. Future research should also focus on the concurrent validity of the CIP with decision-making variables such as career decision-making difficulties (Gati, Krausz, \& Osipow, 1996) and other emerging constructs linked in the literature with aspects of decision making including emotional intelligence (Di Fabio \& Palazzeschi, 2008, 2012; Di Fabio, Palazzeschi, \& Bar-On, 2012). 


\section{Conclusion}

The experiential data from using the CIP with Italian university students suggest that the CIP is particularly useful and valuable in terms of enabling Italian students to explore their career-related narratives in service of constructing their careers and themselves and designing successful lives. The CIPyielded satisfactory results with regard to, among other things, trustworthiness and positive intercorrelations with the SDS.

Despite some limitations, the CIP appears to be a promising instrument that can be used to facilitate qualitative assessment and augment quantitative assessment, allowing exploration of interest areas using career story narratives and enabling the construction of career life trajectories for life design.

\section{References}

Barclay, R. S. (In press). Assessing interests: A career construction perspective. In A. Di Fabio, \& J. G. Maree (Eds), Psychology of career counseling: New challenges for a new era. Hauppauge, NY: Nova Science.

Barclay, R. S., \& Wolff, L. A. (2011). Exploring the career construction interview for vocational personality assessment. Journal of Vocational Behaviour, 81, 370-377.

Creswell, J. W. (2007). Qualitative inquiry and research design: Choosing among five approaches (2nd ed.). London, UK: Sage Publications.

Di Fabio, A. (2012, July). Narratability and career construction: empirical evidence of intervention effectiveness. State-of-the-Science lecture, 30th International Congress of Psychology, Cape Town, South Africa.

Di Fabio, A., \& Maree, J. G. (2011). Group-based life design counseling in an Italian context. Journal of Vocational Behavior, 80, 100-107.

Di Fabio, A., \& Maree, J. G. (in press). Effectiveness of the Career Interest Profile (CIP). Journal of Employment Counseling.

Di Fabio, A., \& Palazzeschi, L. (2008). Indécision vocationnelle et intelligence émotionnelle: Quelques données empiriques sur un échantillon d'apprentis italiens [Career decision difficulties and emotional intelligence: Some empirical evidence in an Italian sample of wage-earning apprentices]. Pratiques Psychologiques, 14, 213-222.

Di Fabio, A., \& Palazzeschi, L. (2012). Incremental variance of the core self-evaluation construct compared to fluid intelligence and personality traits in aspects of decision-making. Personality and Individual Differences, 53, 196-201.

Di Fabio, A., Palazzeschi, L., \& Bar-On, R. (2012). The role of personality traits, core self-evaluation and emotional intelligence in career decision-making difficulties. Journal of Employment Counseling, 49, 118-129.

Duarte, M. E. (2010, July). Restructuring career counseling: objectives and instruments. In Life Design Symposium, convenor R. Van Esbroeck. Symposium held at the 27th International Congress of Applied Psychology, Melbourne, Australia.

Gati, I., Krausz, M., \& Osipow, S. H. (1996). A taxonomy of difficulties in career decision making. Journal of Counseling Psychology, 43, 510-526.

Gevers, J., Du Toit, R., \& Harilall, R. (1995). Manual for the Self-Directed Search (SDS). Pretoria, South Africa: Human Sciences Research Council.
Hall, B. A., Halstead, M. E., \& Taylor, T. R. (1992). Manual for the administration of the Rothwell-Miller Interest Blank. Pretoria, South Africa: HSRC.

Hartung, P. (2011). Career construction: Principles and practice. In K. Maree (Ed.), Shaping the story: A guide to facilitating narrative counselling (pp. 103-119). Rotterdam, The Netherlands: SensePublisher .

Holland, J. L. (1959). A theory of vocational choice. Journal of Counseling Psychology, 6, 35-44.

Holland, J. L., Powell, A. B., \& Fritzsche, B. A. (1994). The Self-Directed Search professional user's guide (4th ed.). Odessa, FL: Psychological Assessment Resources.

Lankton, S. R., \& Lankton, C. H. (2011). The answer within. Bethel, CT: Crown Publishing House Ltd.

Maree, J. G. (2006). Manual for the Career Interest Profile. Randburg, South Africa: Jopie van Rooyen \& Partners.

Maree, J. G. (2007). The Career Interest Profile (1st ed.). Randburg, South Africa: Jopie van Rooyen \& Partners.

Maree, J. G. (2009). The Career Interest Profile (2nd ed.). Randburg, South Africa: Jopie van Rooyen \& Partners.

Maree, J. G. (2010a). The Career Interest Profile (3rd ed.). Randburg, South Africa: Jopie van Rooyen \& Partners.

Maree, J. G. (2010b). Using early memories in career-story interviewing. In J. G. Maree (Ed.), Career counselling: Methods that work (pp. 167-199). Cape Town, South Africa: Juta.

Maree, J. G. (2012a). A (guided) meta-reflection theory of career counseling: A case study. South African Journal of Higher Education, 26, 670-690.

Maree, J. G., \& Sommerville, J. (2008). Development of a post-modern career interest questionnaire. Journal for Psychology in Africa, 17, 125-30.

Maree, K. (Ed.). (2007). Shaping the story: A guide to facilitating narrative career counselling. Pretoria, South Africa: Van Schaik.

McMahon, M., \& Patton, W. (2002). Using qualitative assessment in career counselling. International Journal for Educational and Vocational Guidance, 2, 51-66.

Parton, D. (1994). Coat of many colors. New York, NY: Harper-Collins.

Polácek, K. (Ed.). (2003). SDS Self-Directed Search, Manuale. Adattamento Italiano. [SDS Self-Directed Search, Manual. Italian Adaptation]. Firenze, Italy: O. S. Organizzazioni Speciali.

Porfeli, E. J. (2003). Designing lives and empowering clients: The case of Sue. Career Development Quarterly, 51, 300-305.

Rehfuss, M. C. (2009). The Future Career Autobiography: A narrative measure of career intervention effectiveness. The Career Development Quarterly, 58(1), 82-90.

Savickas, M. L., \& A. R. Spokane (Eds.). Vocational interests: meaning, measurement, and counseling use. Palo Alto, CA: Davies-Black.

Savickas, M. L. (2005). The theory and practice of career construction. In S. D. Brown \& R. W. Lent (Eds.), Career development and counseling: Putting theory and research to work (pp. 42-70). Hoboken, NJ: Wiley.

Savickas, M. L. (2009). Career-style counselling. In T. J. Sweeney (Ed.), Adlerian counselling and psychotherapy: A practi- 
tioner's approach (5th ed., pp. 183-207). New York, NY: Routledge.

Savickas, M. L. (2010, July). Life Designing: Framework and introduction. Paper presented at the 27th International Congress of Applied Psychology, Melbourne, Australia.

Savickas, M. L. (2011, September). Life Design Counseling: From practice to theory. Keynote address presented at international conference "Vocational Designing and Career Counseling: Challenges and new Horizons", Padova, Italy.

Savickas, M. L., Nota, J., Rossier, J. P., Dauwalder, M. E., Duarte, J., Guichard, . . Van Vianen, A. E. M. (2009). Life designing: A paradigm for career construction in the 21th century. Journal of Vocational Behavior, 75, 239-250.

Whitley, B. E. (2002). Principles of research in behavioural science (2nd ed.). New York, NY: McGraw-Hill.

\section{Endnotes}

${ }^{1}$ The extracts have been translated into English with only light editing to preserve their authenticity.

\section{Author Notes}

We would like to express our gratitude to the 178 participants who took part in the research and to Tim Steward for editing this article. 
